\title{
Cloud Computing Awareness in Malaysia Construction industry
}

\author{
Kai Chen Goh , Kamalludin Bilal, Hui Hwang Goh, Sulzakimin Mohamed, Chang Saar Chai, Hun Chuen \\ Gui
}

\begin{abstract}
The construction industry has been treated by fragmentation, lack of integration and complexities in processes and activities which could ultimately bring a negative impact to the construction project success. Therefore, collaboration is very important with the purpose to improve the productivity and effectiveness of construction management and to ensure the efficient utilization of resources. Cloud computing is the latest technology which has acted as a platform to support access to applications, information and services by using only an internet connection. However, it is doubt that the construction stakeholders are aware and use the cloud computing. Thus, the purpose of this research is to determine the awareness of cloud computing and identify the reasons of engagement with cloud computing in Malaysia construction industry. This research was focused on the main contractors within Johore Bahru only. In this research, the research method used quantitative approach and descriptive analysis includes frequency analysis and mean score to interpret the data. From the finding of the research, the Malaysian construction professions have the awareness on cloud computing. However, their level of knowledge is at low level. The concept of cloud computing is still new and it is still in the infant stage of its development in Malaysia construction industry.
\end{abstract}

Index Terms: Construction Industry, Awareness, Construction Collaboration Tools, Cloud Computing

\section{INTRODUCTION}

Integration, collaboration, and communication within a multidisciplinary team of project stakeholders are the key to achieve the goals of a construction project. Therefore, these indicators serve to improve the productivity and effectiveness of construction management and to guarantee the efficient utilization of resources.

Construction is an informative-intensive industry since information delivery is the key to guarantee the success of construction projects in achieving their specific objectives [2]. However, the use of traditional paper document delivery systems can obstruct the way information is communicated

Revised Manuscript Received on August 18, 2019

Kai Chen Goh, Department of Construction Management, Universiti Tun Hussein Onn Malaysia, Parit Raja, Johor, Malaysia.

Kamalludin Bilal, Department of Construction Management, Universiti Tun Hussein Onn Malaysia, Parit Raja, Johor, Malaysia.

Hui Hwang Goh, School of Electrical Engineering, Guangxi University, Nanning, Guangxi Province, China.

Sulzakimin Mohamed, Department of Construction Management, Universiti Tun Hussein Onn Malaysia, Parit Raja, Johor, Malaysia.

Chang Saar Chai, School of Engineering, Swinburne University of Technology Sarawak Campus, Kuching, Sarawak, Malaysia.

Hun Chuen Gui, Department of Quantity Surveying, Universiti Malaysia Sarawak, Kota Samarahan, Sarawak, Malaysia. and exchanged between various stakeholders involved in the entire building lifecycle [11]. Besides, these problems cause friction, financial expense and delay.

In order to overcome problems in construction management, modern project management approaches and tools have been invented. The technological advancement is seeking for the improvement to reduce the project duration and costs along with the better productivity, efficiency and effectiveness in the entire building lifecycle [15]. Cloud computing is the latest technology as the next revolution that will influence how efficiently and effectively the internet and information systems could operate and be used worldwide. In the construction industry, cloud computing is also an emerging technology that promotes a collaborative process.

\section{LITERATURE REVIEW}

Cloud Computing is the latest technology which has been established by the IT industry [5]. Basically, it can be defined as a timely, cost effective and energy-efficient technology which supports access to applications, information and services, such as storage, networks, hardware infrastructures and servers, without restrictions of time and place using only an internet connection.

According to [3], there are three broad types of cloud computing include Infrastructure as a Service (IaaS), Platform as a Service (PaaS) and Software as a Service (SaaS). Besides that, there are four delivery models (deployment models) of cloud computing including public cloud, private cloud, community cloud and hybrid clouds.

There are five main benefit of using cloud computing in the construction industry [13].

Mobile Accessibility - The ease with which cloud-based services may be accessed enables field staff to get the information they need at anywhere.

Scalability - The resources can be deployed very fast from the cloud, cloud computing makes it easier for companies to scale their services, whether up or down [3]. Therefore, this in turn results in more efficient use of resources.

Reduced Needfor In-house IT - Cloud computing can also reduce the stakeholder's need for in-house IT staff [12]. Construction stakeholders can save operational costs, maintenance costs and purchasing costs.

Lower Fixed Costs - Cloud computing is economical as the customers pay only what they used in the cloud computing [12]. Fixed costs associated with software and hardware has been eliminated since capitalizing on cloud

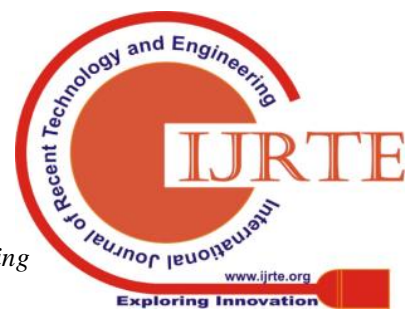


computing only requires internet access.

Collaboration - Cloud applications can be used to share project schedules, drawing, inventory totals, receipts, invoices, and other information among the various stakeholders [12]. Besides, the researchers also stated that the ease and accessibility of cloud-based applications and files can enable that information to be created once and then shared across organizations. In addition, stakeholders can more easily collaborate on updating and reviewing important information while work is underway.

\section{METHODOLOGY}

If you are using Word, use either the Microsoft Equation Editor or the MathType add-on (http://www.mathtype.com) for equations in your paper (Insert | Object | Create New | Microsoft Equation or MathType Equation). "Float over text" should not be selected.

\section{RESULTS AND FINDINGS}

\section{A. General Details of Respondents}

The percentage of the grade of respondents' company were included of G7 (27\%), G6 (23\%), G5 (34\%), and G4 and below (16\%). In addition, about $26 \%$ of the respondent companies were having number of employees between 1 to 9 persons. Moreover, about $46 \%$ of the respondents companies were having 10 to 50 employees. Then, $24 \%$ of respondent company having 51 to 250 employees and $4 \%$ of respondent company were having more than 250 employees. There were about $26 \%$ of the respondents who having professional experience between 1 to 3 years. Furthermore, there were about $25 \%$ of the respondents had experience between 3 to 5 years in their professions. Then, this was followed by $39 \%$ of the respondents owned experience between 5 to 10 years and $11 \%$ of the respondents possessed professional experience 10 years and above.

\section{B. Awareness of Cloud Computing}

You hear more and more about cloud computing in construction industry these days. The results shows that over half $(52 \%)$ of the respondents agreed that they heard about cloud computing these days, with about $50 \%$ of the respondents agreed and $2 \%$ of the respondents strongly agreed. Furthermore, about $31 \%$ of the respondents given moderate responses on that statement, which indicated they were moderately aware on cloud computing. However, about $17 \%$ of the respondents were not aware on cloud computing. Thus, it can be concluded that majority (83\%) of the respondents aware of cloud computing.

The Malaysian construction industries are still not clear enough on cloud computing yet. There were about $74 \%$ of the respondents agreed and 5\% of the respondents strongly agreed. Moreover, about $20 \%$ of the respondents were given moderate in response. On the other hand, only $1 \%$ of the respondents disagreed and no respondents strongly disagreed about the statement. Thus, it can be concluded that cloud computing concept still not clear enough by the construction professions in Malaysia at this moment.

\section{Knowledge about Cloud Computing}

Majority (66\%) of the respondents were poor and bad in cloud computing knowledge. There were about $65 \%$ of the respondents claimed that they were poor in cloud computing knowledge while $1 \%$ of the respondents were bad in cloud computing knowledge. There are about $31 \%$ of the respondents have fair knowledge with cloud computing. Only $3 \%$ of the respondents considered themselves good in cloud computing knowledge. No respondents were found to be expert in cloud computing knowledge. Overall, it indicates that the level of cloud computing knowledge among respondents was at low level.

\section{Willingness to Outsource IT Parts to Cloud Service Provider}

Willingness to outsource IT parts to cloud service provider. There are about $58 \%$ of the respondents claimed that they are currently lack of knowledge needed to take decisions of moving into cloud computing. This is supported by results from the previous question of the knowledge of cloud computing and it indicates that the level of cloud computing knowledge among respondents was at low level. On the other hand, there are about $31 \%$ of the respondents mentioned that cloud computing is a viable option only for the long term (i.e. after then next 3 years). This is followed by $4 \%$ of the respondents who are not interest to use and implement cloud computing and $3 \%$ of the respondents who were interested to implement cloud computing in the short/medium term (i.e. within the 12 months). Besides, $4 \%$ of the respondents claimed that they are using cloud computing currently. Thus, it can concluded that most of the respondents are lacking of knowledge to take decisions of moving into cloud computing.

\section{E. Types of Business Processes to be Outsource to Cloud Computing}

Types of business processes to be outsource to cloud computing service provider. There are about $82 \%$ of the respondents claimed that accounting and financial is the most possible business process which can be outsourced to cloud computing service provider. Besides, more than half of the respondents $(56 \%)$ mentioned that human resource management is the second possible business process which can be moved into the cloud. Other than that, there is about $51 \%$ of the respondents agreed that project management is the third possible business process which can outsourced to cloud computing service provider. Then, this is followed by payroll management (10\%), and procurement management (9\%). Overall, accounting and financial is the most possible business process which can be outsourced to cloud computing service provider.

\section{F. Current Approach Used in Construction Industry}

Current approach of respondents to manage, control and update the latest information, drawing and documents of project. Mostly (98\%) of the respondents were using hard

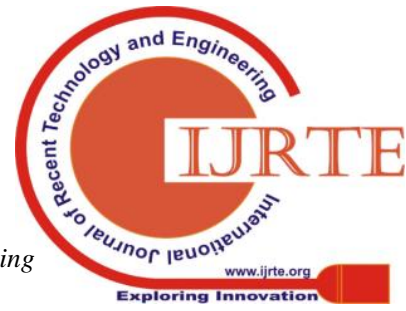


copy documents to manage, control and update the latest information, drawing and documents of project. Besides, majority $(94 \%)$ of the respondents claimed that email is also one of the current approaches of respondents to manage, control and update the latest information, drawing and documents of project. Other than that, there is about 55\% of the respondents mentioned that WhatsApp was also one of the current approach used in the construction industry. However, there is only $4 \%$ of respondents were using cloud computing to manage, control and update the latest information, drawing and documents of project. This implies that the use of cloud computing in the construction industry is still at a very low level and not commonly using by the construction professions yet.

\section{G. Agreement Level toward Statements Related to Cloud Computing Based on the Respondents' Working Experience}

Agreement level toward statements related to cloud computing based on the respondents' working experience. Respondents were categorized into two groups which were more than four years working experiences and less than four years working experiences with 52 and 50 respondents respectively. Respondents were asked to indicate their agreements on the statement related to cloud computing by using the likert- scale ranged from "strongly disagree" to strongly agree". computing helps to access the needed documents, drawing, and information anywhere". More than half $(52 \%)$ of the respondents with less than four years working experience agreed with the statement, about $32 \%$ of the respondents claimed that they were moderated to the statement and only $16 \%$ of them were disagreed with the statement. On the other hand, there are about $38 \%$ of the respondents with more than four years working experience were agreed with the statement, around $38 \%$ of the respondents were moderated to the statement and $24 \%$ of them were disagreed with the statement.

Agreement level of statement of "Cloud computing is the future of project information management system in construction industry". Majority $(72 \%)$ of the respondents with less than four years working experience were agreed with the statement, about $28 \%$ of the respondents were moderate to the statement and there is no respondents were disagreed with the statement. However, about $44 \%$ of the respondents with more than four years working experience were agreed with the statement, around $48 \%$ of the respondents were moderated to the statement and there is $8 \%$ of them disagreed with the statement.

Overall, it can concluded that the knowledge of respondents who have more than four years of working experience on the cloud computing is higher than those who have less than four year of working experience.

\section{H. Reasons Behind Your Possible Engagement with Cloud Computing}

Reasons behind your possible engagement with cloud computing. Majority of respondents were considered the top
The agreement level toward the statement of "Cloud

reason of engagement to adopt cloud computing was easy and mobile accessibility which help the cloud user to use through smartphones, laptops or tablets anywhere, which had the highest mean score among other reasons, with the mean score of 4.15. Furthermore, the second reason to implement cloud computing was avoiding capital expenditure in hardware, software, IT support, and information security, which got the second highest mean score of 3.83. From the responses, increasing computing capacity and business value was the third reason to implement the cloud computing which got the mean score of 3.59. Next, remove economic/expertise barriers to modernize business process was rated as the fourth reason to apply cloud computing, with the mean score of 3.47. On the other hand, respondents were rated the collaboration of construction project information management as the fifth reasons of engagement, with the mean score of 3.32. Then, this was followed by flexibility and scalability of IT resources with the mean score of 3.05 , as well as reduced the need for In-House IT infrastructure and staff with the mean score of 2.35 .

Overall, the range of mean score of reasons of engagement to cloud computing was from 2.35 to 4.15 . It indicates all of the reasons are considered relevant to the implementation of cloud computing in the construction, but in different degree of importance. Based on the perceptions of respondents, the top three reasons of engagement of cloud computing were easy and mobile accessibility which help the cloud user to use through smartphones, laptops or tablets anywhere, avoiding capital expenditure in hardware, software, IT support, and information security and also increasing computing capacity and business value.

\section{DISCUSSION}

Awareness of cloud computing. According to the questionnaire results, majority of the respondents were lack of cloud computing knowledge. We can conclude that majority of the respondents did not possess cloud computing knowledge and working experience with cloud computing at this moment. This is important findings, which suggest that there is still a need for professional development and education on cloud computing.

Knowledge about cloud computing. Most of the respondents claims they are currently lack knowledge needed to take decisions of moving into cloud computing. However, the vanguard already resides in the cloud based on the results from the global survey of over 900 executives in 15 countries [9]. Thus, there is a need of government to put in efforts to promote the technology of cloud computing in construction industries.

Current approach level used in construction industry. More than half (52\%) are using hard copy documents to perform and conduct estimating, takeoff, big management and other business processes and mostly (98\%) of the respondents were using hard copy documents to manage, control and update the latest information, drawing and documents of project. However, [11] mentioned that there are a dwindling few in the industry that go by 
the 'old fashioned' way which means of using hard copy document, but they are slowly being pushed out due to market forces. Besides, he also noted that implementing specialized construction software is critical for remaining competitive in a tough industry. Therefore, construction players should follow up the trend to avoid eliminated by the market.

Types of business processes to be outsource to cloud computing. There are $82 \%$ of the respondents claimed that accounting and financial is the most possible business process which can be outsourced to cloud computing service provider. Yet, the accounting is not the top business process requested to move into cloud by the respondents in the survey with only $18 \%$ [5]. Furthermore, from the finding, 51\% of the respondents agreed that project management is the third possible business process which can outsourced to cloud computing service provider. However, the survey results showed that the top business process requested by respondents to move into cloud was project management with about $33 \%$ [5]. The result of this question in this research is different from the previous research.

Reasons of possible engagement with cloud computing. There are $81 \%$ of the respondents claimed that easy and mobile accessibility which help the cloud user to use through smartphones, laptops or tablets anywhere is the leading reason of engagement to wider take up of cloud computing, which got the highest mean scores of 4.15. This finding is supported by another research, stated that the mobile accessibility feature of cloud-based services enables field staff to get the information they need at anywhere which bypasses the need to fax or email information to the home office [14]. Besides, the increased popularity and use of laptops, smartphones, and tablets means that stakeholder's IT network can now extend to virtually any location [13]. It is because crucial information does not reside within an internal server, it can be accessed more easily from mobile endpoints.

Moreover, respondents claimed that the avoiding capital expenditure in hardware, software, IT support, and information security is the one of reason of engagement with cloud computing which get second highest mean score of 3.83. One of the benefits of cloud is economical [12]. The researchers stated that the customers pay only what they used in the cloud computing. Fixed costs associated with software and hardware has been eliminated since capitalizing on cloud computing only requires internet access. Moreover, cloud computing resource usage can be measured, controlled, and reported providing transparency for both the provider and consumer of the utilised service. Cloud computing services use a metering capability which enables to control and optimise resource use. This implies that just like air time, electricity or municipality water, IT services are charged per usage metrics - pay per use.

Increasing computing capacity and business value as considered as one of the reason of engagement with cloud computing, which got the mean scores of 3.59. The amazon's cloud computing services can help building teams, owner and material suppliers meet, share ideas and basically do business more effectively and without delay [1]. The use of cloud computing in any given company can help give them the edge over their competition, which ultimately increases

business value. Any business is to increase profit, while decreasing cost [7]. Amazon's cloud computing has the ability to decrease costs in several ways but simultaneously increase profit, build better business relations, and remain current on technological advances.

Based on the questionnaire results, most of the respondents claimed that there is a need of in-house IT infrastructure and staff if cloud computing is used and implemented. Reduced need for in-house infrastructure and staff have been ranked with lowest mean score of 2.35 by the respondents which implied that it is not the reason to engage with cloud computing among the reasons. However, this finding of the research results is differed from various researches. For example, cloud computing can reduce the stakeholder's need for in-house IT staff [12]. This is supported that by another publication [10], which mentioned that company do not have to invest in a large number of powerful servers; the IT department of companies can then use the computing power of the cloud to enhance or change the internal computing resources. Besides, another benefit mentioned by researcher is that cloud computing drives to lower software costs. The different of the finding is believed to be related to the knowledge of cloud computing. From the finding, $66 \%$ of the respondents claimed that they were lack of knowledge about cloud computing.

Future strategy in the construction industry. The use of cloud computing is future strategy in the construction industry which is potentially meet the particular needs of construction [8]. From the finding, over half (72\%) of the respondents were agreed that there is a potential that cloud computing will be widely adopted by construction professions to manage the information of building in projects in the future. The research results indicate that construction project managers are comfortable with Cloud-based systems, as 57 percent of participants access their application over the Web.

The technology of cloud computing is an upcoming tool for construction professions in Malaysia. However, the concept of cloud computing is still vague and not widely adopted in industry. According to the results of questionnaire, easy and mobile accessibility and education, avoiding capital expenditure in hardware, software, IT support, and information security, and increasing computing capacity and business value were the top three reasons of engagement with cloud computing in construction professions based on the perceptions of respondents.

\section{CONCLUSION}

Overall, this research provides a view of current status of cloud computing in Malaysian construction professions. This research were determined the awareness of cloud computing in Malaysia construction industry. Besides, this research also identified the reason of engagement with cloud computing in Malaysia construction industry. The Malaysian construction professions have the awareness on cloud computing. However, their level of knowledge is at low level. Most of the respondents were agreed 
that Malaysian construction industry was still not clear enough on cloud computing yet. The concept of cloud computing is still new and unfamiliar in Malaysian construction industries. Cloud computing technology is still in the infant stage of its development in Malaysia although there are many countries have implement cloud computing in the construction projects.

The engagement reasons to implement cloud computing in Malaysia construction industry were (i) easy and mobile accessibility which help the cloud user to use through smartphones, laptops or tablets anywhere, (ii) avoiding capital expenditure in hardware, software, IT support, and information security, and (iii) increasing computing capacity and business value. Furthermore, there is a need to develop the cloud computing software, applications and tools which is suitable and relevant to be used in Malaysia construction industry. Besides, some efforts need to be carried out by Government and private sector for widely adopt cloud computing technology in Malaysian construction industry. The education or training course related with cloud computing should be organized by Government, organization and local universities as well. Additionally, cloud computing is a new knowledge field in Malaysia and thus more research related with cloud computing is needed.

\section{ACKNOWLEDGMENT}

The authors express gratefully acknowledgment to the industry stakeholders for their valuable contributions towards the success of this research. This research is fully funded by Universiti Tun Hussein Onn Malaysia (UTHM) under Vot: U887, Tier 1 Grant Scheme and Vot: H257, Tier 1 Grant Scheme.

\section{REFERENCES}

1. Aljabre, A. (2012). Cloud computing for increased business value Journal of Business and Social Science, 3(1), 234-240. Retrieved from

thttp://library.capella.edu/login?url=http://search.proquest.com.library.c apella.edu/docview/913056373 ?accountid=27965

2. Anumba, C. J., Pan, J. \& Issa, R. R. A. (2008). 'Collaborative Project Information Management in a Semantic Web Environment. Engineering,' Construction and Architectural Management, 15 (1), 78-94.

3. Chong, H. Y., Wong, J. S., \& Wang, X. (2014). An explanatory case study on cloud computing applications in the built environment Automation in Construction, 44 152-162. http://doi.org/10.1016/j.autcon.2014.04.010

4. Cloud Computing. (2010). 'Cloud Computing Use Cases,' A White Paper Produced by the Cloud Computing Use Case Discussion http://opencloudmanifesto.org/Cloud_Com puting_Use_Cases_Whitepaper-4_0.pdf

5. Finch, J. (2013) Construction Software Buyer Report - 2014. Retrieved from: onstruction-buyer-report-2014/

http://www.softwareadvice.com/resources/c

6. Fathi, M., Anumba, C., \& Carrillo, P. (2006). Context Awareness in Construction Management-Key Issues \& Enabling Technologies. The Joint International Conference on Construction Culture, Innovation and Management (CCIM), (Ccim), 425-435. Retrieved from http://scholar.google.com/scholar?hl=en\&bt $\mathrm{nG}=$ Search\&q=intitle:CONTEXT+AWARENESS+IN+CONSTRUCT ION+MANAGEMENT+KEY+ISSUES+\&+ENABLING+TECHNOL OGIES\#0

7. Greggo, A. (2009). Cloud computing in the enterprise: An overview. Paper presented at the Enterprise Computing Conference.

8. Hore, A. V., West, R., \& Redmond, A. (2010). Software as a Service and its Application in the Irish Construction Industry, (Aec). Group, Version 4.0. Retrieved from:

9. Matuszak, G. \& Lamoureux, T. (2011). Embracing the cloud Retrieved from: https://www.kpmg.com/Global/en/IssuesAndInsights/ArticlesPublication s/Documents/e mbracing-cloud.pdf

10. Miller, M. (2008).Cloud Computing: Web-Based Applications That Change the Way You Work and Collaborate Online, Indianapolis: Que Publishing.

11. Goh, K. C., Goh, H. H., Yap, A. B. K., Masrom, M. A. N., \& Mohamed, S. (2017). Barriers and drivers of malaysian BIPV application: Perspective of developers. Paper presented at the Procedia Engineering.

12. Tao, J., Marten, H., Kramer, D., \& Karl, W. (2011). An intuitive framework for accessing computing clouds. Procedia Computer Science, 4, 2049-2057. http://doi.org/10.1016/j.procs.2011.04.224

13. Thomas, B. Y. B. J. (2012). CLOUD COMPUTING for Construction Accounting. Retrieved http://www.weaver.com/sites/default/files/C FMABuildingProfits-Jul-Aug2012CloudComputing-ByBrianThomas_1.pdf

14. Zhang, S., Yan, H., \& Chen, X. (2012). Research on Key Technologies of Cloud Computing. Physics Procedia, 33, 1791-1797. http://doi.org/10.1016/j.phpro.2012.05.286.

15. Soon Ern, P. A., Kasim, N., Abd Hamid, Z., \& Kai Chen, G. (2017). Critical ICT-inhibiting factors on IBS production management processes in the malaysia construction industry. Paper presented at the IOP Conference Series: Materials Science and Engineering, , 245(3) doi:10.1088/1757-899X/245/3/032067

\section{AUTHORS PROFILE}

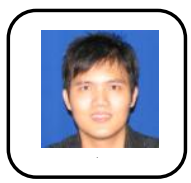

First Author Associate Professor Ts. Dr. GOH Kai Chen is currently Associate Professor, Construction Management of Universiti Tun Hussein Onn Malaysia (UTHM). With a $\mathrm{PhD}$ in built environment and engineering, he was awarded as Young Lecturer for the National Blue Ocean Strategy-Joint Initiative Programme (NBOS-PILS) under the Ministry of Higher Education, Malaysia in 2015. Dr. Goh plays active roles in professional bodies. He is the Fellow of ASEAN Academy of Engineering and Technology (FAAET), Professional Technologist (Building \& Construction) under Malaysia board of Technologist, Incorporate member of The Charted Institute of Building, UK and an accredited facilitator of Green Building Index (GBI) Malaysia. His research interests include construction financial management, sustainability, sustainable infrastructure management, life-cycle costing, techno-entrepreneurship, decision support, renewable-energy and construction management.

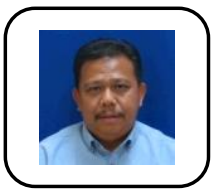

Second Author LAr. Dr. Kamalludin bin Bilal is currently Senior Lecturer, Construction Management of Universiti Tun Hussein Onn Malaysia (UTHM). With a $\mathrm{PhD}$ in facility management from Universiti Teknologi Malaysia, Dr. Kamalludin plays active roles in professional bodies. He is the corporate member of Institute Landscape Malaysia, Professional Technologist (Building \& Construction) under Malaysia board of Technologist. His research interests include facility management, sustainability, sustainable infrastructure management, landscape, decision support and construction management.

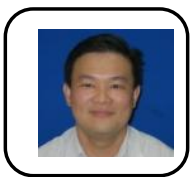

Third Author Prof. Ir. Dr. Hui Hwang Goh is currently Professor of School of Electrical Engineering, Guangxi University, Nanning, Guangxi Province, China. Prof. Ir Dr. Goh plays active roles in professional bodies. He is he is the fellow of Institution of Engineering and Technology (FIET), UK (2016), the fellow of Institution of Engineers, Malaysia (FIEM, 2016), the fellow of ASEAN Academy of Engineering and Technology (FAAET), the Honoree of the Ten Outstanding Young Malaysian by Junior Chamber International in 2014, elected Associate member, Academy Sciences Malaysia since 2016, invited to serve as academic advisory board member to Universities such as UTEM, Swinburne University Sarawak Campus and AIMST University, provide advice to Ministry of Higher Education (MOHE), Ministry of Education (MOE), and many more. His current research interests include the area of power electronics, motor drives control, renewable energies and artificial intelligence control. 
Fourth Author Dr. Sulzakimin Hj Mohamed received Bsc (Hons.) Surveying \& Mapping Sciences from Univ East London UK, Msc Construction Management from Glasgow Caledonian Univ UK and $\mathrm{PhD}$ in Technology Management from Universiti Tun Hussein Onn Malaysia, in 1998, 2002 and 2014, respectively. He is currently a Lecturer with the Department of Construction Management, Faculty of Technology Management \& Business, Universiti Tun Hussein Onn Malaysia. His current research interests include the area sustainable development, environment, renewable energies and local government.

Fifth Author Dr. Chang Saar Chai is the Director for Digital Technology International Centre in Malaysia. He is currently attached to Swinburne University of Technology Sarawak Campus. He is well-respected not only in his unparalleled professional industry track records and high ethical standards, but also being a committed person in teaching, learning and research disciplines.

Sixth Author Sr Gui Hun Chuen is a Professional Quantity Surveyor registered with BQSM and RISM with a Construction Management Master's Degree who is especially keen in knowledge sharing and knowledge transfer. He is known among his peers to be cheerful, trustworthy, self-disciplined, meticulous and tech-savvy. Having worked in the construction industry for 11 years, he joined UNIMAS as a senior lecturer since 2018. His main areas of interest are solid waste management and green construction. In 2019, Sr Gui and his team won the Bronze Award for their research on Building Information Modelling (BIM) during the Innovation Technology Expo (InTEX) 2019. 